\title{
CFD modeling of 2D asymmetric entry impact along with horizontal velocity
}

Modelado del impacto en dos dimensiones de secciones típicas de botes de planeo con entrada asimétrica y velocidad horizontal

\begin{abstract}
The 2D impact phenomenon in calm water, considering asymmetric entry and asymmetric entry with horizontal velocity is studied. The analysis was performed by using a commercial CFD software (STAR$\mathrm{CCM}+($ )). The results obtained from the simulations are: pressure distribution, force and roll moment. The study was carried out for typical planing boat sections. Furthermore, the critical conditions required for flow separation from the keel are also determined. The results are compared with models and results obtained from some authors and they present very good agreement.
\end{abstract}

Key words: 2D Impact, CFD modeling, asymmetric entry, keel flow separation.

\section{Resumen}

En este trabajo se modela la entrada asimétrica de secciones con ángulo de astilla muerta variable y velocidad horizontal con la ayuda del software CFD Star-CCM+, con el cual se determinan la distribución de presión, la variación de fuerza y momento de rolido durante impacto. Los resultados obtenidos son comparados con los modelos de otros autores para entrada asimétrica logrando gran similitud. Se introduce el efecto de la velocidad horizontal y se analiza el comportamiento de este tipo de secciones, y también se evalúan las condiciones críticas que dan origen a la separación del flujo de la quilla para diferentes cuñas.

Palabras claves: Impacto 2D, entrada asimétrica, superficie libre, modelado CFD.

Date Received: August 20th, 2011 - Fecha de recepción: 20 de Agosto de 2010

Date Accepted: January 17th, 2011 - Fecha de aceptación: 17 de Enero de 2011

\footnotetext{
${ }^{1}$ Department of Mechanical Engineering. Universidad del Norte. Barranquilla, Colombia. e-mail: algarinr@uninorte.edu.co, ingmec_83@ yahoo.com.mx

${ }^{2}$ Department of Mechanical Engineering. Universidad del Norte, Barranquilla, Colombia. e-mail: abula@uninorte.edu.co

${ }^{3}$ Research, Development and Innovation Direction. Science and Technology Corporation for the Development of the Naval, Maritime and Riverine Industry in Colombia. Km 9, Via Mamonal. Cartagena D. T., Colombia. e-mail: otascon@cotecmar.com
} 


\section{Symbols}

$\begin{array}{ll}B & \text { Beam length. } \\ C_{f y} & \text { Horizontal force coefficient. } \\ C_{f z} & \text { Vertical force coefficient. } \\ C_{m v} & \text { Rolling moment coefficient. } \\ C_{p} & \text { Pressure coefficient. } \\ f_{y}^{p} & \text { Horizontal Force per unit length. } \\ f_{z} & \text { Vertical Force per unit length. } \\ m_{x} & \text { Rolling Moment per unit length. } \\ p & \text { Pressure. } \\ t & \text { Time. } \\ w & \text { Vertical velocity. } \\ v & \text { Horizontal velocity. }\end{array}$

\section{Greek Symbols}

$\begin{array}{ll}\tau & \text { Time coefficient. } \\ \beta & \text { dead rise angle. } \\ \rho & \text { Fluid density. }\end{array}$

\section{Introduction}

The 2D impact phenomenon has been studied through the application of added mass theory, boundary valued problems, and CFD applications. Wagner (1932) applied added mass theory to obtain the lift force in a wedge section, as presented in Fig.1. He also evaluated the pressure distribution assuming potential flow and applying energy conservation. Tveitnes (2001) also studied the impact applying added mass theory. He also calculated the lift force and concluded that the hydrodynamic force experienced by a wedge section under symmetric entry and constant velocity entry, is generated by the variation of mass and flow moment. Moreover, the force exerted during the impact linearly increases as the section submerges and reaches the flow separation at the knuckle. This separation occurs when $z / d=2 / \pi$. From that point, the moment decreases. The behavior in this zone was empirically obtained, showing that the force remains constant after a certain time. The added mass and flow moment coefficients were empirically determined as functions of the dead rise angle. Caponnetto et al., (2003) generalized the impact for symmetric entry for sections with variable dead rise angle. He also evaluated the flow separation for section including knuckles. Vorus (1996) studied the 2D impact with symmetric entry for a section with variable dead rise angle, solving the problem as a boundary value problem, assuming potential flow. Based on Vorus (1996), Xu et al., (1998) analyzed the 2D impact with asymmetric entry, calculating the pressure, force and roll moment in the section. Seif et al., (2005) simulated the impact by using CFD tools for circular and wedge sections, considering symmetric and asymmetric entry over calm waters with vertical velocity. The results obtained are very close to Wagner (1932) and Toyama (1993). According to results, the surface tension and viscosity effects can be neglected, but the gravity effect must be considered.

Fig. 1. Geometric characteristics of a wedge

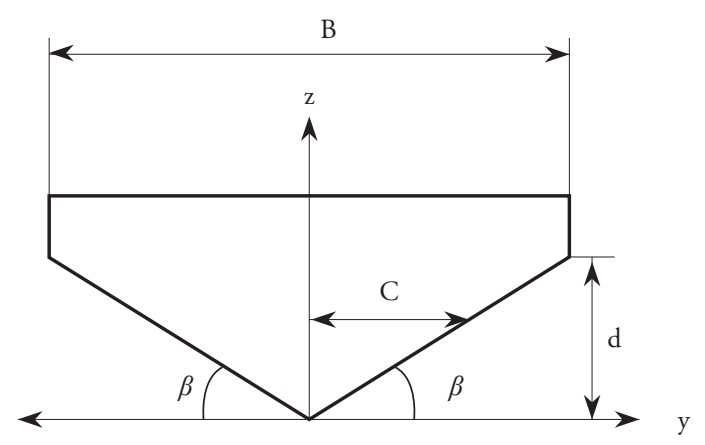

\section{Mathematical Model}

To present the results, some variables were defined according to the following equations:

Vertical force Coefficient

$$
C_{f z}=\frac{f_{z}}{\frac{1}{2} \rho w^{2} B}
$$

Horizontal force Coefficient

$$
C_{f y}=\frac{f_{z}}{\frac{1}{2} \rho w^{2} B}
$$


Rolling moment Coefficient

$$
C_{m x}=\frac{m_{x}}{\frac{1}{2} \rho w^{2} B^{2}}
$$

Pressure coefficient

$$
C_{p}=\frac{p}{\frac{1}{2} \rho w^{2}}
$$

Time coefficient

$$
\tau=\frac{w t}{\frac{1}{2} B}
$$

\section{Numerical Computation}

The conservation of mass and momentum equations were numerically solved. The commercial CFD software (STAR-CCM+) was used as a tool to solve the differential equations that govern the phenomenon. The software uses finite volume approximation, and the equations obtained from the discretization procedure are solved by using an Algebraic Multi-Grid (AMG) solver. The models used to simulate the phenomenon are: multiphase mixture (water-air), inviscid flow, segregated flow, and unsteady (implicit method). For the fluids, water was modeled as an incompressible liquid, while air was considered an ideal gas. To confirm that the viscosity and the surface tension could be neglected, some simulations were carried. The conclusions attained are similar to Seif et al., (2005), where the effects of these two variables were discarded.

The size of the computational domain was developed changing the width and the height to model the impact in calm waters over an infinite canal. The peak force during impact was monitored, and the grid size was selected when the variation of the peak force was less than $1 \%$. The final width and height of the domain were $9 \mathrm{~B}$ to $10 \mathrm{~B}$, and $5 \mathrm{~B}$ to $12.5 \mathrm{~B}$, respectively. The time step was also varied considering the impact velocity and it ranged from 0.008 to $0.016 \mathrm{~d} / \mathrm{w}$.
The mesh was developed by using polyhedral elements and it was divided in three regions, as shown in Fig. 2a. Region 1 is mainly water; region 2 is a phase mixture, where the hull gets in contact with the water and the air and the free surface is generated. This area is very important for the study and because of this the mesh was refined, as shown in Fig. 2b. Region 3 is mainly air.

Figure 2a. Wedge Section with symmetric entry. Computational domain mesh

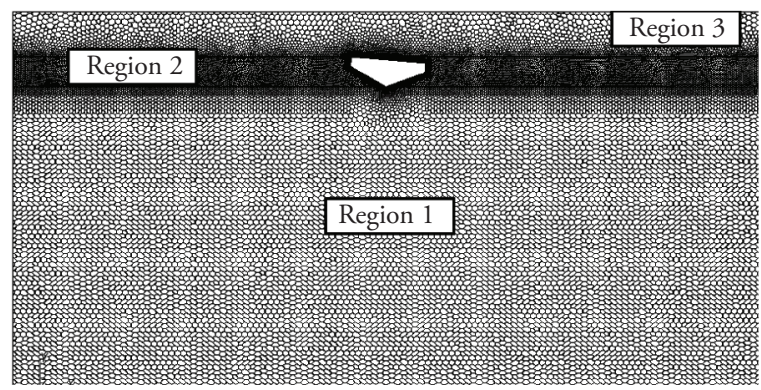

Fig. 2b. Wedge Section with symmetric entry. Mesh in the hull

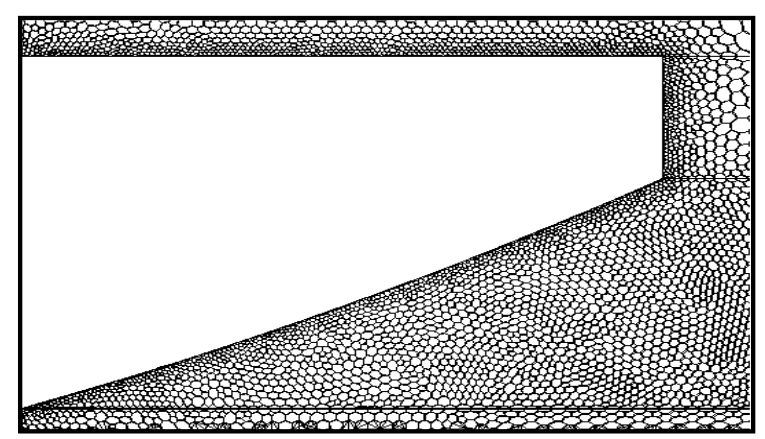

Figs. $2 \mathrm{a}$ and $2 \mathrm{~b}$ show the mesh after a refinement process for a section. The base size of the polyhedral element took values ranging between $0.15 \mathrm{~B}$ and $0.25 \mathrm{~B}$. For Regions 1 and 3, the values ranged between $0.045 \mathrm{~B}$ and $0.100 \mathrm{~B}$. For Region 2 , the values ranged from $0.0075 \mathrm{~B}$ to $0.020 \mathrm{~B}$. The residuals values for the impact force, keel pressure, and roll moment were used as the stop criteria, and the magnitude of the global residual was limited to $10^{-8}$, while the maximum number of inner iterations in each time step was limited to 30 . 


\section{Results and Discussion}

The boundary conditions considered for modeling the asymmetric entry are: constant atmospheric pressure at the top boundary, velocity entry on the base and vertical boundaries, and wall at the hull. The geometries simulated are presented in Fig. 3, and the results are compared with Xu et al., (1998).

Fig. 3. Sections evaluated by Xu et al. (1998)

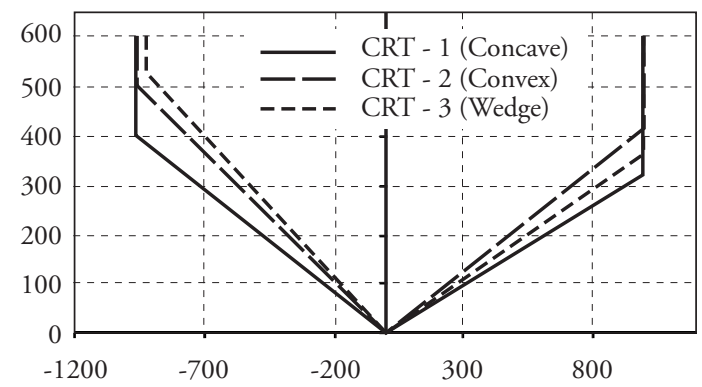

\section{Asymmetric Entrance - No horizontal velocity}

Fig. 4, 5 and 6 show the results of vertical force coefficient variation with time for sections CTR-1, CTR-2 and CTR-3.

Fig. 4. $\mathrm{C}_{\mathrm{fz}}$ vs $\tau$, CRT-1 (Concave section)

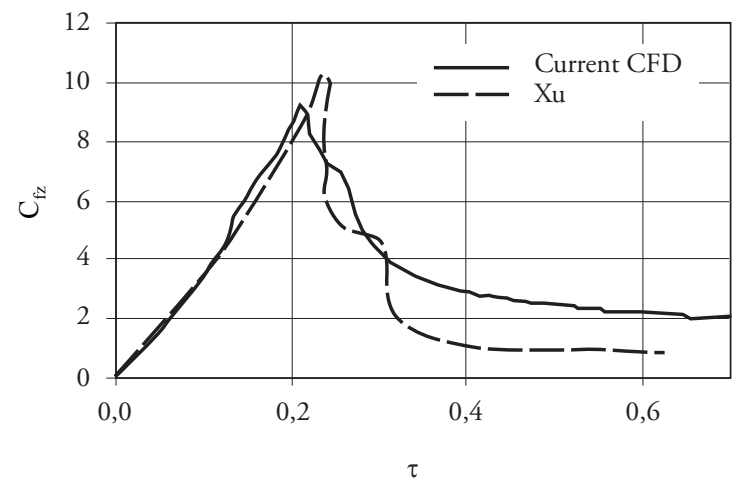

The force on the impact increases while the section immerses until the point where flow separation begins from the knuckle in side 1; after that, the force decreases. There is a second force peak, which appears when the flow separates on side 2 ; after that, the force decreases. The results show good agreement with the results by Xu L. (1998) before the flow separation of the knuckle. The maximum error in the peak force is $15 \%$ respect to the models by Xu L. (1998).

Fig. 5. $\mathrm{C}_{\mathrm{fz}}$ vs $\tau$, CRT-2 (Convex section)

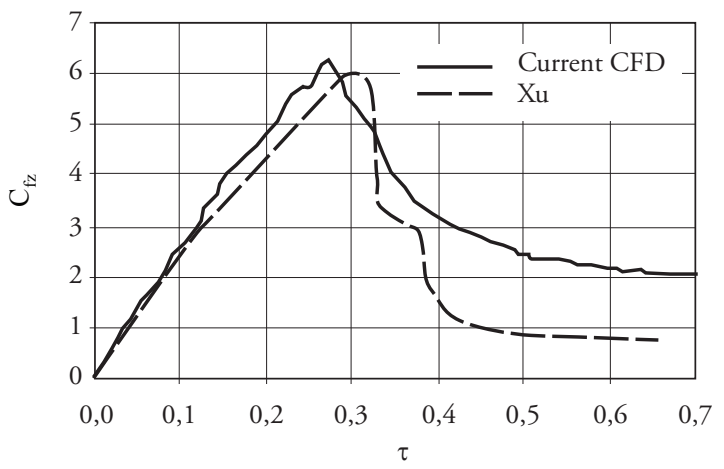

Fig. 6. $\mathrm{C}_{\mathrm{fz}}$ vs $\tau$, CRT-3 (Wedge section)

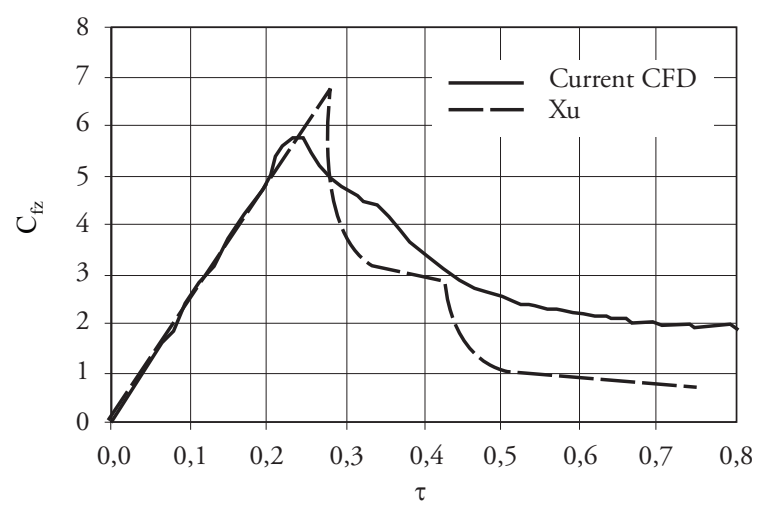

Figs. 7, 8, and 9 show the results of the variation of roll moment coefficient with respect to time for sections CRT- 1, CRT-2, and CRT-3. As the section enters the water, the pressure distribution is asymmetric, generating a restoring moment (roll moment). The figures show that the moment increases up to the point where the flow separates from side 1. At this point, the pressures in this side are higher. When the flow separates from the knuckle, the pressure on side 1 and the moment decrease. On the other hand, the pressure on side 2 reaches a higher value than side 1 , reversing the direction of the roll moment. This reversing is presented until the flow separates from side 2.

Figs. 7, 8, and 9 show great similarity with the results reported by Xu L. (1998). The maximum error in the peak moment is $29 \%$, comparing 
with that reported by Xu L. (1998). Also, the time required for flow separation is shorter, meaning that the jet velocity of the simulation is higher than that found by Xu L. (1998).

Fig. 7. $\mathrm{C}_{\mathrm{mx}}$ vs $\tau$, CRT-1 (Concave section)

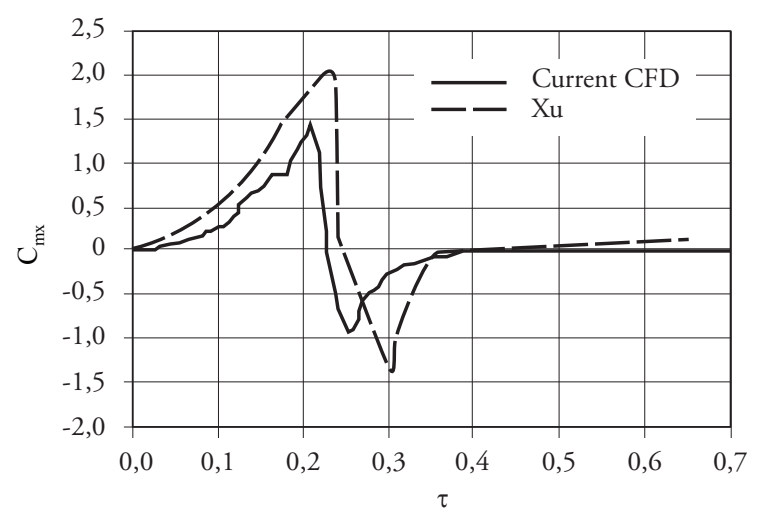

Fig. 8. $\mathrm{C}_{\mathrm{mx}}$ vs $\tau$, CRT-2 (Convex section)

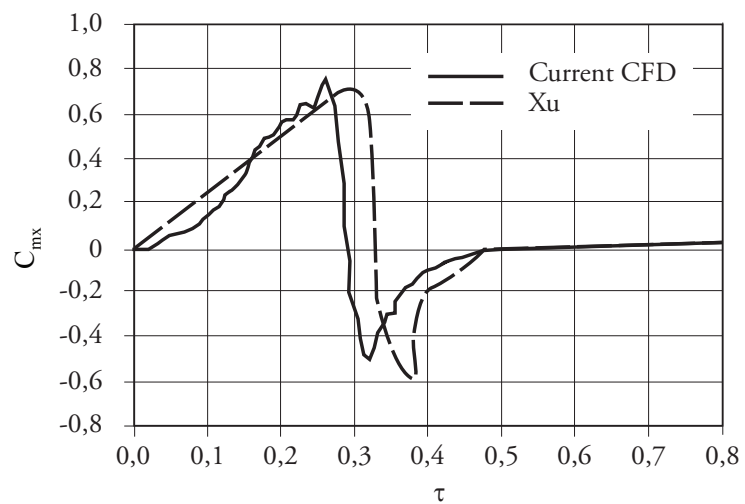

Fig. 9. $\mathrm{C}_{\mathrm{mx}}$ vs $\tau$, CRT-3 (Wedge section)

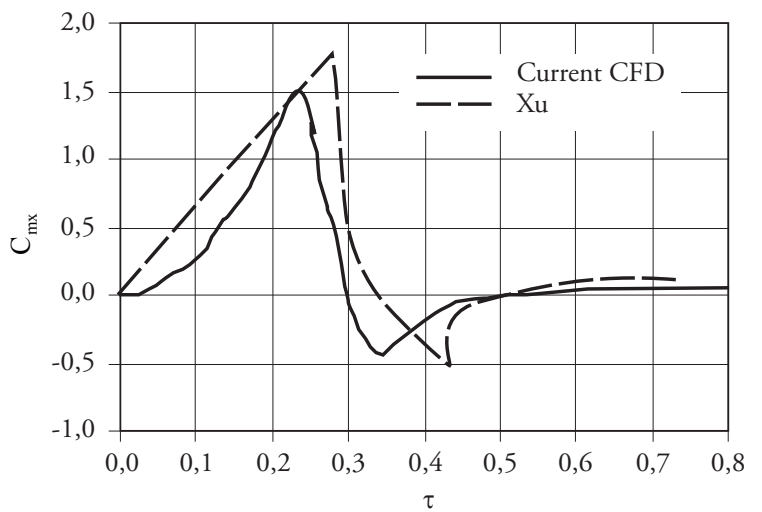

\section{Asymmetric Entrance - Horizontal velocity}

The results attained are shown for vertical force and roll moment, and the sections considered are CRT-1, CRT- 2, and CRT-3. The velocity ratios considered for the simulation were $\mathrm{v} / \mathrm{w}=-1.0,0.0$, and 1.0. Figures 10, 11, and 12 show the vertical force coefficient variation with time for sections CRT-1, CRT-2, and CRT-3. Similar behavior is noticed when comparing with asymmetric entrance with no horizontal velocity. The force reaches peaks at the points where the flow separates from the knuckles in both sides. Furthermore, the time required for flow separation is independent from the velocity ratio. The main effect of the velocity ratio is noticed for the peak on side 2 ; the value obtained increases as the velocity ratio increases. Also, after the flow separation is attained, the force decreases faster when the velocity ratio is increased.

Fig. 10. $\mathrm{C}_{\mathrm{fz}}$ vs $\tau$, CRT-1, asymmetric entry with horizontal velocity (Concave section)

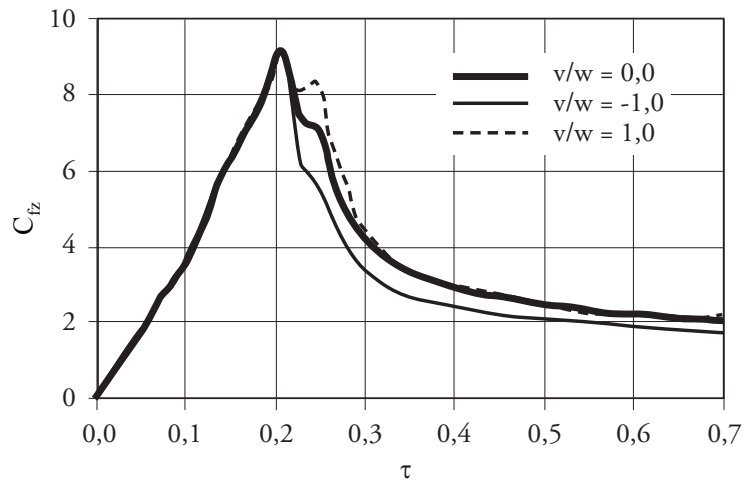

Fig. 11. $\mathrm{C}_{\mathrm{fz}}$ vs $\tau$, CRT-2, asymmetric entry with horizontal velocity (Convex section)

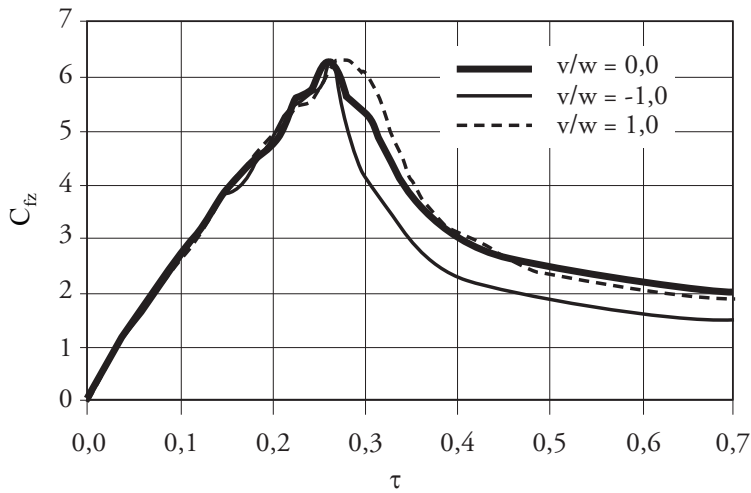


Fig. 12. $\mathrm{C}_{\mathrm{f}_{\mathrm{z}}}$ vs $\tau$, CRT-3, asymmetric entry with horizontal velocity (Wedge section)

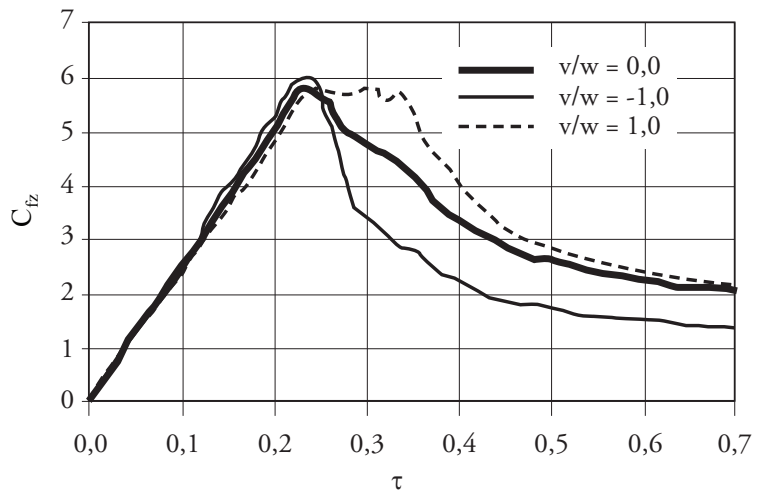

Figs. 13, 14, and 15 show the variation of the roll moment with time for sections CRT-1, CRT2 , and CRT-3. It is noticed that the behavior is different from that observed for asymmetric entry without horizontal velocity. There are two force peaks corresponding to flow separation from the knuckles. The velocity ratio has an important effect over the pressure distribution, generating instability over the section. In Figures 13, 14 and 15 , for a velocity ratio of 1.0 , instability is noted due to side 2 apparent impact velocity higher than apparent impact velocity on side 1 .

Fig. 13. $\mathrm{C}_{\mathrm{mx}}$ vs $\tau$, CRT-1, asymmetric entry with horizontal velocity (Concave section)

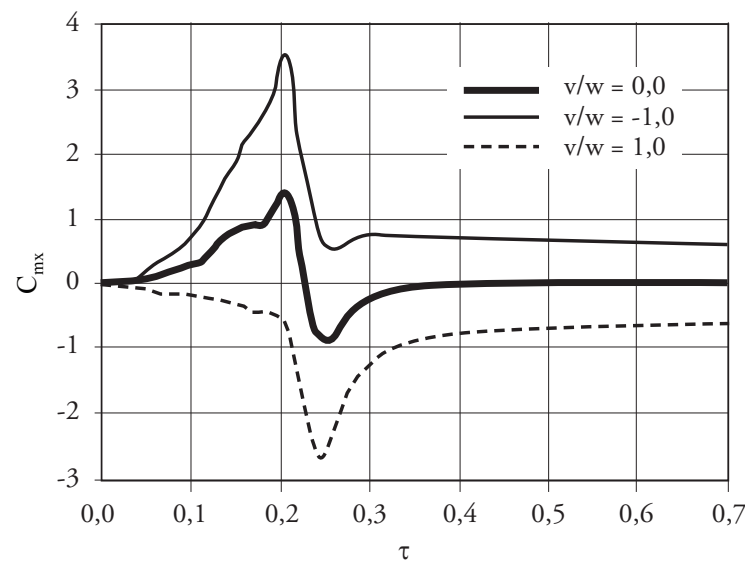

Transition from Type A to Type B Flow

As a section enters in the water under the appropriate conditions of asymmetric angle, $\varphi$, and
Fig. 14. $\mathrm{C}_{\mathrm{mx}}$ vs $\tau$, CRT-2, asymmetric entry with horizontal velocity (Convex section)

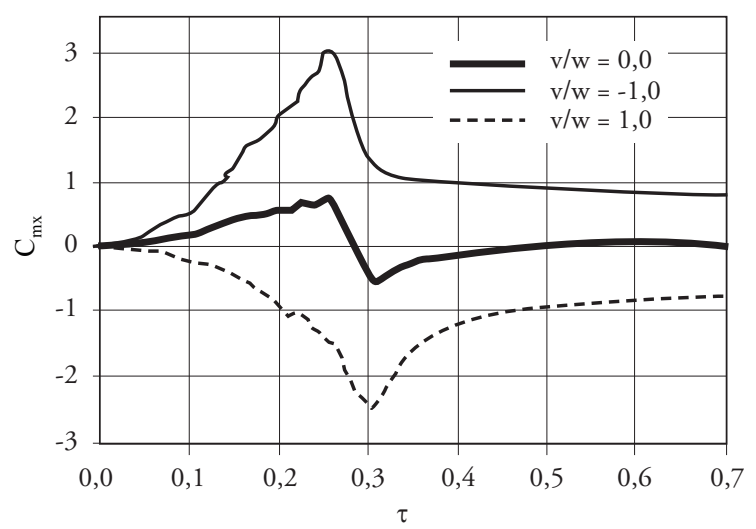

Fig. 15. $\mathrm{C}_{\mathrm{mx}}$ vs $\tau$, CRT-1, asymmetric entry with horizontal velocity (Wedge section)

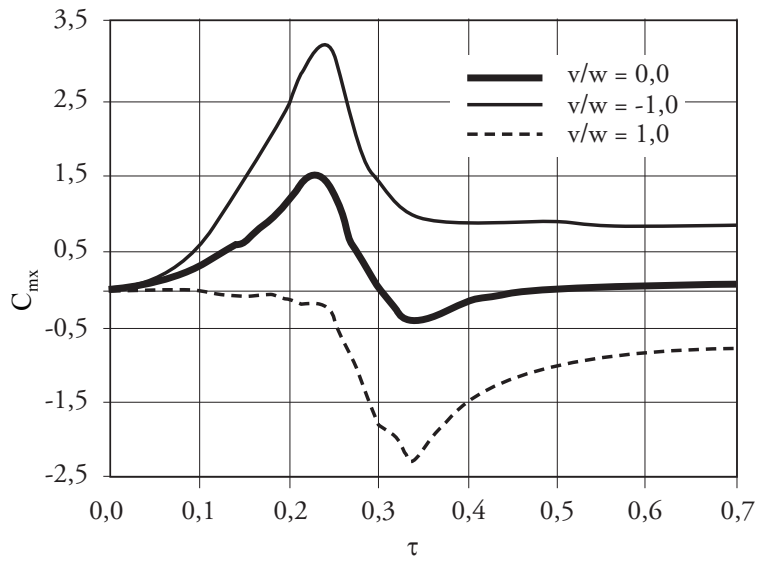

Fig. 16. v/ w vs. $B$ critical for the flow separation of the keel for symmetric entry

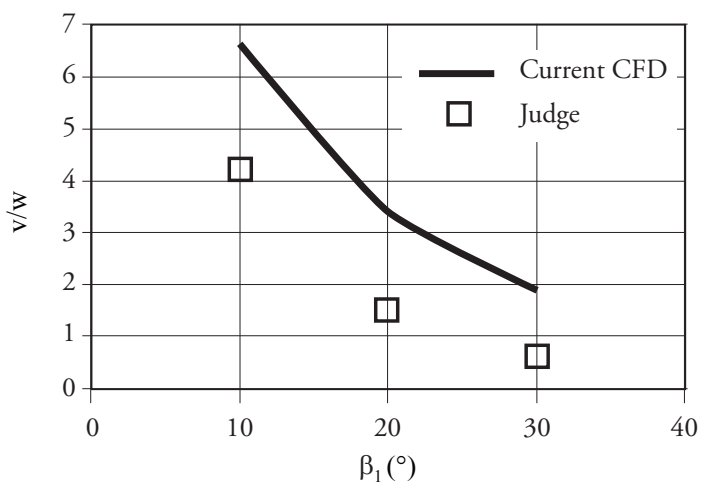

velocity ratio, $\mathrm{v} / \mathrm{w}$, it is possible that flow separation occurs from the keel. To determine the zone where the transition occurs, a slamming wedge 
section with horizontal and vertical velocities was simulated. To find the critical condition, the water volume fraction in the hull was monitored from the beginning of the impact. The results are shown in the Figs. 16 and 17.

Fig. 16 presents the critical velocity ratio, which creates flow separation from the keel for asymmetric entry of a wedge section. The graphic shows that a lower horizontal velocity component is required as the dead rise angle of the section increases.

Fig. 17. 82 vs. 81 critical for the flow separation of the keel for asymmetric entry
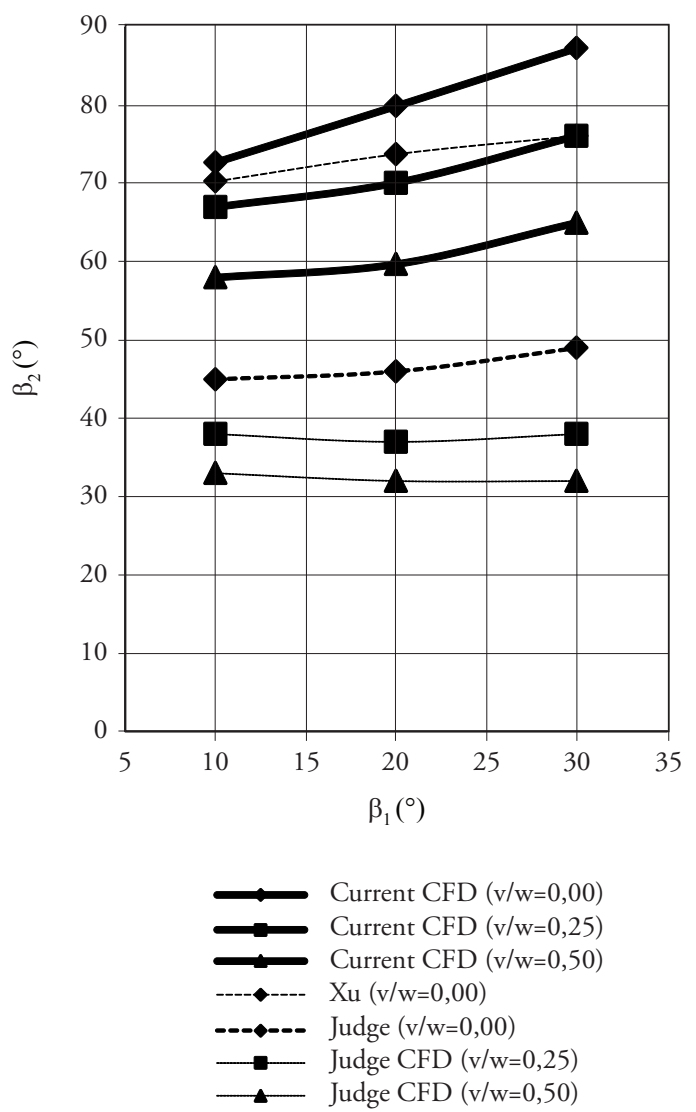

Fig. 17 shows the critical $\beta_{2}$ angle, which creates flow separation from the keel for asymmetric entry of a wedge section. A higher angle $\beta_{2}$ is required as the $\beta_{1}$ angle increases. Furthermore, as the velocity ratio increases, the flow separation from the keel occurs at a smaller $\beta_{2}$ angle.

\section{Conclusions}

The 2D impact was modeled for asymmetric entry of different sections by using STAR -CCM+ (C) The pressure distribution was obtained, as well as the force and roll moment variation with time. The results present great similarity with those reported by Vorus (1996) and Xu L. (1998). The effect of the horizontal velocity was also analyzed for wedge sections with variable dead rise angle, determining the influence of this parameter in the force and roll moment.

The critical condition for flow separation from the keel was evaluated. The results obtained are similar, but the values are higher than the results reached by Xu L. (1998) and Judge (2000).

\section{References}

ALGARIN, R. "Modelamiento del impacto en dos dimensiones de secciones asimétricas con velocidad horizontal con aplicaciones en el diseño de botes de Planeo". [M.Sc. thesis]. Barranquilla: Universidad del Norte. Programa de ingeniería Mecánica, 2010. 120p.

SEIF, M., MOUSAVIRAAD, S., SADDATHOSSEINI, S., AND BERTRAM, V. "Numerical Modeling of 2-D Water Impact in One degree of Freedom". Síntesis Tecnológica. No. 2, Vol. 2, November 2005, p. 79-83.

CAPONNETTO, M., SÖDING, H., AND AZCUETA, R. "Motion Simulations for Planing Boats in Waves". Ship Technology Research, Vol. 50, 2003, pp. 182-196.

TVEITNES, T. "Application of Added Mass theory in planing [Ph.D. Thesis]". Glasgow: University of Glasgow. Department of Naval Architecture and Ocean Engineering, 2001, 339p.

VORUS, W. S. "A flat cylinder theory for vessel impact and steady planing resistance". Journal of Ship Research. No. 2, Vol. 40, June 1996, p. 89-106. 
WAGNER, H. "Über stoss - und Gleitvorgänge an der Oberflüshe von Flüssigkeiten. eitschrift für Angewandte Mathematik und Mechanik". No. 4, Vol. 12, August 1932, p. 193-215.

XU, L., TROESCH, A., AND VORUS, W. "Asymmetric Vessel Impact and Planing Hydrodynamics". Journal of Ship Research, No. 3, Vol. 42, September 1998, p. 187-198.

CD-ADAPCO. 'Star-CCM+ Version 3.06.006 User Guide', 2008.

JUDGE C. AND TROESCH A. "Asymmetry and horizontal velocity during water impact", [on-line]. Available at: http://www.eng. tau.ac.il/-greg/ABST.pdf/judge.pdf/ judgeWWWFB2.pdf, 2000.
TOYAMA Y. "Two-dimensional water impact of unsymmetrical bodies". Journal of Soc. Naval Arch. Japan. Vol. 173, 1993, p. 285-291.

XU, G.D. "Numerical simulation of oblique water entry of an asymmetrical wedge". Journal of Ocean Engineering. Vol. 35, August 2008, p. 1597-1603.

YOON, B.S. Flow Separation At The Initial Stage Of The Oblique Water Entry Of a [on- line]. Available at: http://www.iwwwfb. org/Abstracts/iwwwfb24/iwwwfb24_53.pdf, 2009. 